University of Nebraska - Lincoln

DigitalCommons@University of Nebraska - Lincoln

May 1999

\title{
Surface composition of $\mathrm{Co}_{x} \mathrm{Ni}_{1-x} \mathrm{O}$ solid solutions by $\mathrm{X}$-ray photoelectron and Auger spectroscopies
}

\author{
M. W. Nydegger \\ University of Nebraska - Lincoln \\ G. Couderc \\ University of Lyon, France \\ Marjorie Langell \\ University of Nebraska - Lincoln, mlangell1@unl.edu
}

Follow this and additional works at: https://digitalcommons.unl.edu/chemistrylangell

Part of the Chemistry Commons

Nydegger, M. W.; Couderc, G.; and Langell, Marjorie, "Surface composition of $\mathrm{Co}_{x} \mathrm{Ni}_{1-x} \mathrm{O}$ solid solutions by X-ray photoelectron and Auger spectroscopies" (1999). Marjorie A. Langell Publications. 14.

https://digitalcommons.unl.edu/chemistrylangell/14

This Article is brought to you for free and open access by the Published Research - Department of Chemistry at DigitalCommons@University of Nebraska - Lincoln. It has been accepted for inclusion in Marjorie A. Langell Publications by an authorized administrator of DigitalCommons@University of Nebraska - Lincoln. 
Published in Applied Surface Science 147:1-4 (May 1999), pp. 58-66. doi:10.1016/S0169-4332(99)00077-X Copyright (C) 1999 Elsevier Sci-

ence B.V. Used by permisssion. http://www.sciencedirect.com/science/journal/01694332

Submitted September 24, 1998; accepted December 23, 1998; published online June 7, 1999.

\title{
Surface composition of $\mathrm{Co}_{x} \mathrm{Ni}_{1-x} \mathrm{O}$ solid solutions by X-ray photoelectron and Auger spectroscopies
}

\author{
M. W. Nydegger, G. Couderc*, and M. A. Langell ${ }^{\dagger}$ \\ Department of Chemistry, University of Nebraska-Lincoln, Lincoln, NE 68588-0304 \\ * Present address: Department of Chemistry, University of Lyon, France. \\ $\dagger$ Corresponding author.E-mail: mlangell@unlinfo.unl.edu
}

\begin{abstract}
The surface and bulk compositions of the mixed metal oxide $\mathrm{Co}_{x} \mathrm{Ni}_{1-x} \mathrm{O}$ have been compared over the entire range of stoichiometry $0 \leq x \leq 1$. The materials, which were formed as polycrystalline solid solutions, were shown to be well-ordered and homogeneous in the bulk, but tend to deviate in their surface composition for $x \gtrsim 0.6$. Auger and X-ray photoelectron spectroscopy gave comparable results and indicated that the surface composition for samples showing deviation from bulk stoichiometry was compatible with the formation of a spinel-like $\mathrm{NiCo}_{2} \mathrm{O}_{4}$ surface phase. XPS binding energies and spectral peak shapes provided information that indicates that the $\mathrm{Ni}^{2+}$ cations occupy octahedral sites, leaving the $\mathrm{Co}^{3+}$ divided between tetrahedral and octahedral occupancy in an inverse spinel structure. The surface spinel shows evidence of oxide defect formation, however, and in the range of the spinel formation yields a second $\mathrm{O} 1 \mathrm{~s}$ peak with binding energy of $531.2 \mathrm{eV}$ that cannot easily be attributed to hydroxyl formation. The oxygen species, which has been reported previously for surface oxidation to produce similar metal oxide compounds, has been attributed to defect lattice oxygen.
\end{abstract}

Keywords: oxides, solid solutions, cobalt oxide, nickel oxide, defects

\section{Introduction}

Transition metal oxides (TMOs) are used in a variety of material applications, including electrochemical devices, gas sensors, and heterogeneous catalysts. The ability to tailor materials within these areas represents an obvious advantage for their improved performance and continued development. For example, $\mathrm{CoO}$ and $\mathrm{NiO}$ find use, individually, as partial oxidation catalysts [1] and as promoters for hydrodesulfurization catalysis [2]. They can also be mixed in all proportions, $\mathrm{Co}_{x} \mathrm{Ni}_{1-x} \mathrm{O}$ with $0 \leq x$ $\leq 1$, to form homogeneous solid solutions in a well-ordered rocksalt crystal structure in the bulk material [3, 4]. As solid solutions, they have been demonstrated to be electrochemically active in redox processes under alkaline conditions [5].

The fact that the two materials so readily form solid solutions results from the close match of their individual unit cell structures. Both are fcc rocksalt and have comparable lattice parameters of $4.1684 \AA$ and $4.2667 \AA$ 
for $\mathrm{NiO}$ and $\mathrm{CoO}$, respectively [6], and at intermediate compositions of $\mathrm{Co}_{x} \mathrm{Ni}_{1-x} \mathrm{O}$, the lattice parameter varies linearly as a function of $x$ [3]. A thermodynamically stable mixed spinel $\left(\mathrm{NiCo}_{2} \mathrm{O}_{4}\right)$ also exists at a composition that is stoichiometrically equivalent in cobalt-tonickel ratio to that of the rocksalt oxide with $x=0.66$ $\left(\mathrm{Co}_{0.66} \mathrm{Ni}_{0.33} \mathrm{O}\right) . \mathrm{NiCo}_{2} \mathrm{O}_{4}$, which adopts an inverse spinel crystal structure, has been studied by X-ray diffraction [7] and bulk spectroscopic techniques [8,9]. The material has also been analyzed for its potential use as an electrocatalyst and has been shown to undergo phase separation at the surface into $\mathrm{NiO}$ and cobalt-enriched spinel $\mathrm{Ni}_{y} \mathrm{Co}_{2+y} \mathrm{O}_{4}$ by XPS [10-12]. Of particular interest in this phenomenon is the differences in oxidation properties of the two rocksalt monoxides. $\mathrm{CoO}$ readily forms layers of the spinel $\mathrm{Co}_{3} \mathrm{O}_{4}$ [13], even under relatively low partial pressures of oxygen. The $\mathrm{Ni}^{3+}$-containing oxides are thermodynamically less accessible, particularly for the binary oxide compounds, and the spinel $\mathrm{Ni}_{3} \mathrm{O}_{4}$ is considerably more difficult to obtain.

We present here surface studies on the series of bulk polycrystalline $\mathrm{Co}_{x} \mathrm{Ni}_{1-x} \mathrm{O}$ rocksalt oxides over the entire range $0 \leq x \leq 1$. The bulk is shown to be homogeneous and in the correct stoichiometry by powder X-ray diffraction. The surface compositional determination is made with Auger electron spectroscopy (AES) and Xray photoelectron spectroscopy (XPS). Analysis of the binding energies and satellite structure of the XPS metal $2 p$ photoemission features is used to provide information on the chemical nature and site occupancy of the metal cation components. We find evidence that the surface composition closely follows that of the bulk for low cobalt (low $x$ ) concentrations, but is nickel-enriched at higher values. Compositions of the nickel-enriched surfaces are consistent with the formation of the spinel $\mathrm{NiCo}_{2} \mathrm{O}_{4}$. As do many late $3 \mathrm{~d}$ TMOs, these materials have localized and highly electron-correlated band structures which lead to characteristic peak shapes in the metal $2 p$ XPS. These and other effects are discussed in greater detail below.

\section{Experimental}

$\mathrm{Co}_{x} \mathrm{Ni}_{1-x} \mathrm{O}$ solid solutions were prepared by mixing $\mathrm{CoO}$ (Alfa Aesar, 95\%) and $\mathrm{NiO}$ (Alfa Aesar, 99\%) in the ap- propriate ratios to generate a series of compounds with a range of cobalt and nickel bulk compositions. After grinding with a mortar and pestle, a pellet was made for each sample in a series of the mixed $\mathrm{CoO} / \mathrm{NiO}$ powders spanning the range $0 \leq x \leq 1$. The pellets were placed into individual quartz capsules, which were evacuated to $3 \times 10^{-5}$ Torr for three days. The capsules were then sealed and placed in a Lindberg Hevi-Duty tube furnace at a temperature of $1233 \mathrm{~K}$ for seven days to allow the cobalt and nickel cations to interdiffuse and form a homogeneous solid solution. Powder X-ray diffraction of a small piece of each pellet was taken with a Rigaku Geigerflex diffractometer using $\mathrm{Cu} \mathrm{K} \alpha$ radiation to show that the samples were homogeneous and to confirm the bulk stoichiometry.

The remaining pieces of the pellets were mounted on a PHI Electronics model 10-504 carousel manipulator which was placed in a 40-1 stainless steel UHV bell jar described in detail previously [14]. The base pressure of this system was approximately $4 \times 10^{-10}$ Torr. XPS and AES data were acquired with a double pass cylindrical mirror analyzer, with AES taken by lockin amplification and XPS by pulse-count detection. AES data were obtained with a $2-\mathrm{keV}$ electron beam at a scan rate of $1.0 \mathrm{eV} / \mathrm{s}$ and a time constant of 0.1 $\mathrm{s}$, and the reported spectra are an average of 10 scans. XPS spectra were obtained using $\mathrm{Mg} \mathrm{K} \alpha$ radiation ( $h v$ $=1253.6 \mathrm{eV}$ ) with a pass energy of $200 \mathrm{eV}$ for broad scan spectra and $50 \mathrm{eV}$ for higher resolution scans in the individual $\mathrm{Co} 2 \mathrm{p}$, Ni 2p, O 1s, and $\mathrm{C} 1 \mathrm{~s}$ photoemission ranges. The data were signal-averaged for at least 200 scans and were taken in increments of 0.1 eV with dwell times of 50-200 ms. The XPS data were calibrated relative to the $\mathrm{O} 1 \mathrm{~s}$ of the rocksalt lattice at $529.5 \mathrm{eV}$, as described below.

Since a small amount of carbon, and potentially hydroxyl or other oxygen-containing impurities, were present on the as-introduced samples, the XPS and AES spectra were collected on the samples before and after a brief $\mathrm{Ar}^{+}$sputtering $\left(3 \times 10^{-5}\right.$ Torr, $0.5 \mathrm{keV}, 1.6 \mu \mathrm{A} /$ $\mathrm{cm}^{2}$ for $5 \mathrm{~min}$ ). The sputtering removed the majority of the carbon, but did not otherwise significantly change the results of the analyses, including $\mathrm{O} /(\mathrm{Co}+\mathrm{Ni})$ and $\mathrm{Co} /$ Ni AES and XPS intensity ratios, which were measured both before and after the $\mathrm{Ar}^{+}$treatment and found to be equivalent to within the error of the measurement. Un- 
less otherwise stated, the data presented below are those subjected to the brief sputtering pretreatment.

\section{Results}

An Auger spectrum of the $\mathrm{Co}_{0.5} \mathrm{Ni}_{0.5} \mathrm{O}$ sample is shown in Figure 1 and is typical of AES data obtained for the $\mathrm{Co}_{x} \mathrm{Ni}_{1-x} \mathrm{O}$ solid solutions. The series of $\mathrm{L}_{3} \mathrm{VV}, \mathrm{L}_{3} \mathrm{M}_{2,3} \mathrm{~V}$, and $\mathrm{L}_{3} \mathrm{M}_{2,3} \mathrm{M}_{2,3}$, transitions characteristic of Auger spectra from $3 \mathrm{~d}$ transition metals, is found at 656,716 , and $775 \mathrm{eV}$ for cobalt and at 716, 783, and $848 \mathrm{eV}$ for nickel in the $\partial N(E) / \partial E$ spectrum, causing the cobalt $\mathrm{L}_{3} \mathrm{M}_{2,3} \mathrm{~V}$ and $\mathrm{L}_{3} \mathrm{M}_{2,3} \mathrm{M}_{2,3}$ peaks to overlap with those of the nickel $\mathrm{L}_{3} \mathrm{VV}$ and $\mathrm{L}_{3} \mathrm{M}_{2,3} \mathrm{~V}$. To estimate the relative metal surface compositions, the $\partial N(E) / \partial E$ spectrum was integrated and the areas under the $\mathrm{L}_{3} \mathrm{M}_{2,3} \mathrm{M}_{2,3}$ core-level transitions were obtained. The nickel $\mathrm{L}_{3} \mathrm{M}_{2,3} \mathrm{~V}$ contribution to the cobalt $\mathrm{L}_{3} \mathrm{M}_{2,3} \mathrm{M}_{2,3}$ intensity was removed by assuming a constant $\mathrm{Ni} \mathrm{L}_{3} \mathrm{M}_{2,3} \mathrm{~V} / \mathrm{L}_{3} \mathrm{M}_{2,3} \mathrm{M}_{2,3}$ integrated intensity ratio of 0.54 , as was found for pure $\mathrm{NiO}$ samples, and subtracting this amount from the combined integrated intensity of the overlapping 775 and $783 \mathrm{eV}$ peaks. The fractional surface concentration of cobalt, $x_{\text {surface }}$, was then estimated using relative Auger yields for the transitions:

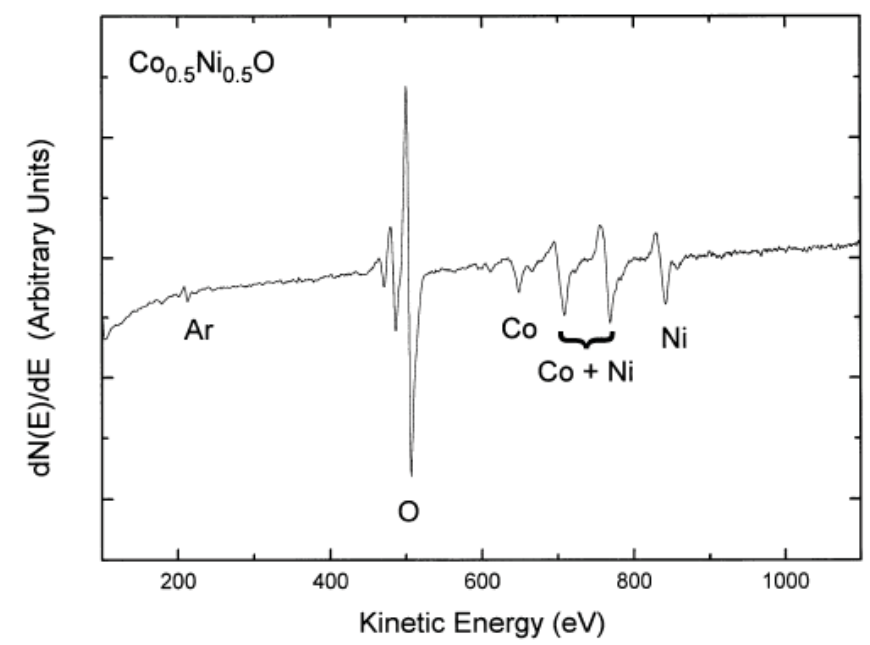

Figure 1. Differential Auger spectrum of the $\mathrm{Co}_{0.5} \mathrm{Ni}_{0.5} \mathrm{O}$ solid solution. The argon impurity results from a brief sputter treatment described in the text. The cobalt $\mathrm{L}_{3} \mathrm{M}_{2,3} \mathrm{~V}$ and $\mathrm{L}_{3} \mathrm{M}_{2,3} \mathrm{M}_{2,3}$ transititions overlap with those of the nickel $\mathrm{L}_{3} \mathrm{VV}$ and $\mathrm{L}_{3} \mathrm{M}_{2,3} \mathrm{~V}$, as labeled and described more fully in the text.

$$
x_{\text {surface }}=\frac{I_{\mathrm{Co}} / S_{\mathrm{Co}}}{I_{\mathrm{Co}} / S_{\mathrm{Co}}+I_{\mathrm{Ni}} / S_{\mathrm{Ni}}} \text {, }
$$

where $S_{i}$ are relative Auger yields for integrated LMM Auger transitions at $2 \mathrm{keV}$, escape depth inclusive, and the $I_{i}$ values are the integrated Auger intensities from the $N(E)$ spectrum. The $S_{i}$ values, which include a dependency on the electron mean free path, were calculated to be 1.36 for the nickel $848 \mathrm{eV}$ transition and 1.31 for the cobalt $775 \mathrm{eV}$ transition by procedures outlined in Refs. $[15,16,17,18]$. The surface composition obtained in this manner is plotted as a function of bulk composition in Figure 2.

For the $\mathrm{Co}_{x} \mathrm{Ni}_{1-x} \mathrm{O}$ solid solutions, the surface and bulk metal compositions are comparable for $x \lesssim 0.6$. Up to this point, $x_{\text {surface }}$ varies linearly with that of the bulk and the two values agree to within error of the accuracy with which the relative Auger yields of Equation 1 can be applied. However, for bulk cobalt concentrations above this value, the surface appears to be pinned at a surface composition equivalent to that expected for the spinel, $\mathrm{NiCo}_{2} \mathrm{O}_{4}(x=0.66$ for the metal ratios) until the material is almost pure $\mathrm{CoO}$.

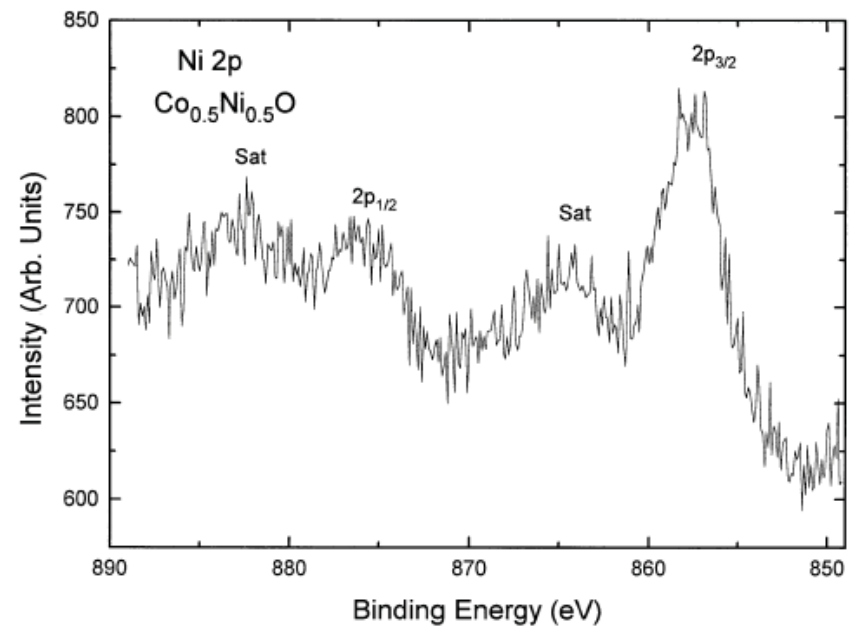

Figure 2. Surface $\left(x_{\text {surface }}\right)$ cobalt concentration as a function of the bulk $\left(x_{\text {bulk }}\right)$ value, measured by Auger spectroscopy. Error bars represent uncertainty in determining peak intensities in the peak fitting procedure. 
The oxygen concentration can also be estimated from the Auger data. In Figure 3, the relative oxygen surface composition:

$$
\frac{C_{\mathrm{O}}}{C_{\mathrm{Co}}+C_{\mathrm{Ni}}}=\frac{I_{\mathrm{O}} / S_{\mathrm{O}}}{I_{\mathrm{Co}} / S_{\mathrm{Co}}+I_{\mathrm{Ni}} / S_{\mathrm{Ni}}}
$$

is plotted as a function of $x$ for the bulk $\mathrm{Co}_{x} \mathrm{Ni}_{1-x} \mathrm{O}$ composition, where $I_{\mathrm{O}}$ is the integrated intensity for the oxygen $\mathrm{KL}_{2} \mathrm{~L}_{2}$ transition in the $N(E)$ Auger spectrum and $S_{\mathrm{O}}$ $=1.35$ is the relative sensitivity factor for the $510 \mathrm{eV}$ oxygen Auger transition. The data span an $\mathrm{O} /(\mathrm{Co}+\mathrm{Ni})$ ratio of $0.76-1.45$ and average to a value of 1.10 , with lower

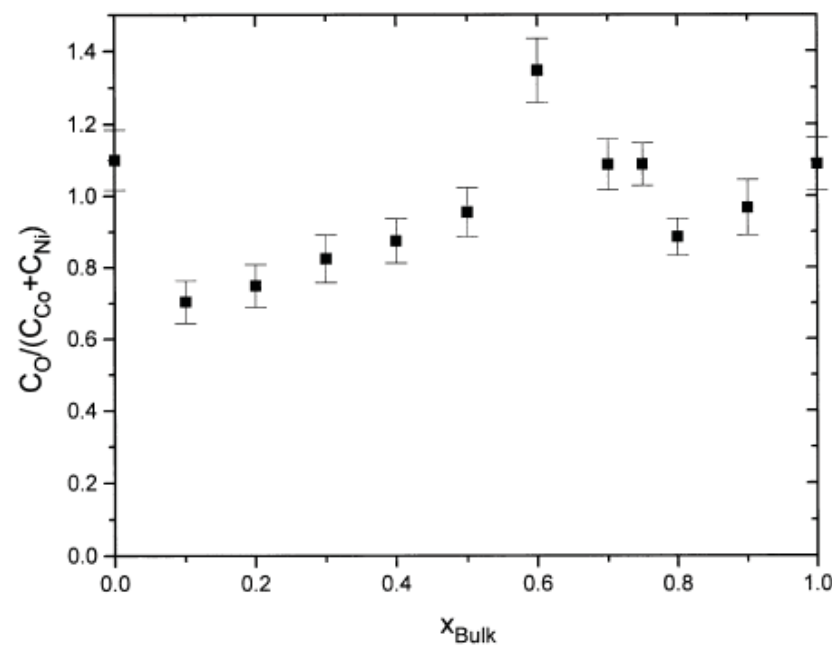

Figure 3. Atomic ratio of oxygen to total metal $(\mathrm{Co}+\mathrm{Ni})$ as a function of the bulk $x$ value, obtained from intergrated Auger spectra as described in the text. Error bars represent uncertainty in determining peak intensities in the peak fitting procedure.

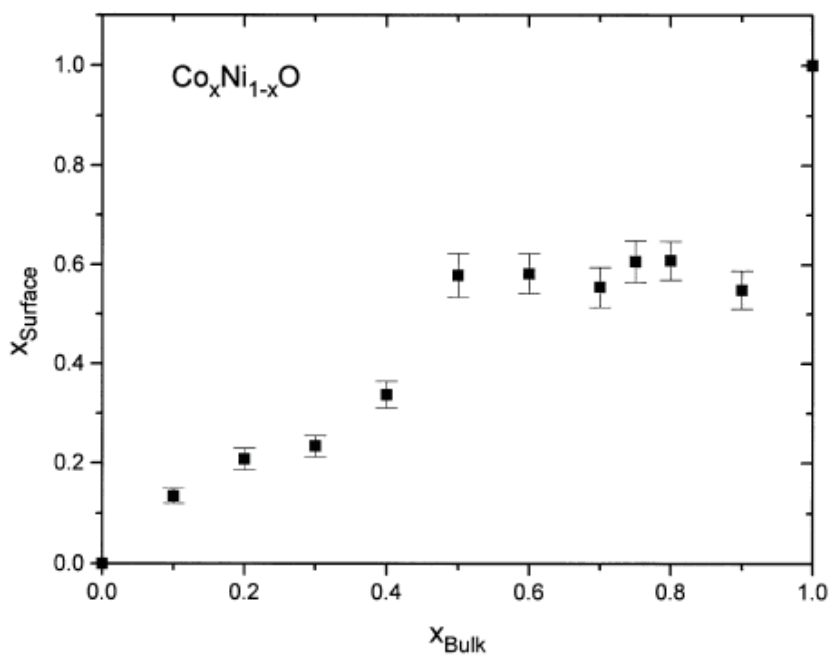

Figure 5. Nickel 2p XPS for the $\mathrm{Co}_{0.5} \mathrm{Ni}_{0.5} \mathrm{O}$ solid solution. values found predominately for low $x$ values. The general trend is consistent with oxidation to a spinel stoichiometry at the bulk cobalt concentration of approximately $x=0.6$, but the effect is more difficult to quantify due to greater scatter in the oxygen data. This effect will be discussed in greater detail below along with additional information contained in the X-ray photoelectron data.

XPS gives further evidence for differences in surface and bulk composition of $\mathrm{Co}_{x} \mathrm{Ni}_{1-x} \mathrm{O}$ solid solutions for $x \gtrsim 0.6$. XP spectra were taken of the cobalt $2 \mathrm{p}$, nickel $2 \mathrm{p}$ and oxygen $1 \mathrm{~s}$ regions, shown in detail in Figure 4, Figure 5 and Figure 6 for the $\mathrm{Co}_{0.5} \mathrm{Ni}_{0.5} \mathrm{O}$ sample. The

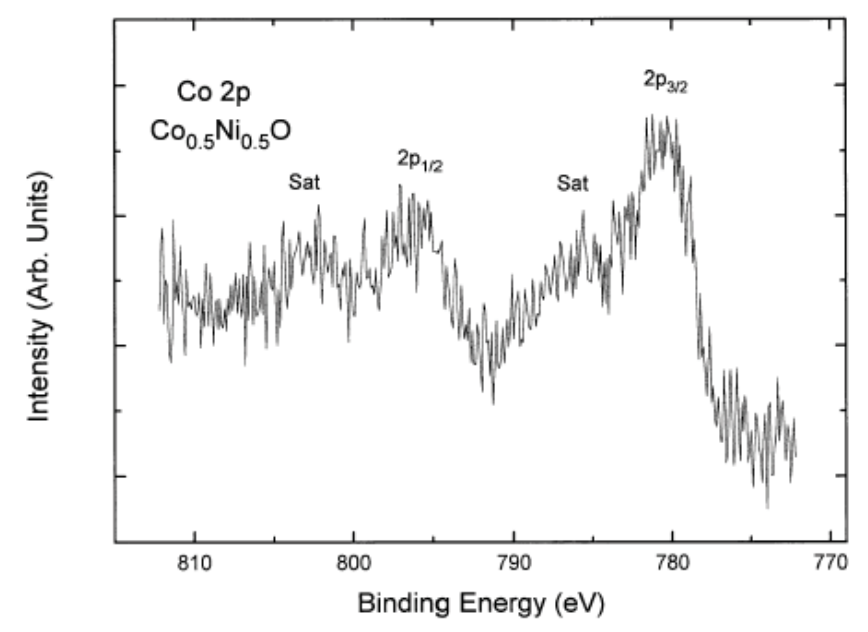

Figure 4. Cobalt $2 \mathrm{p}$ XPS for the $\mathrm{Co}_{0.5} \mathrm{Ni}_{0.5} \mathrm{O}$ solid solution.

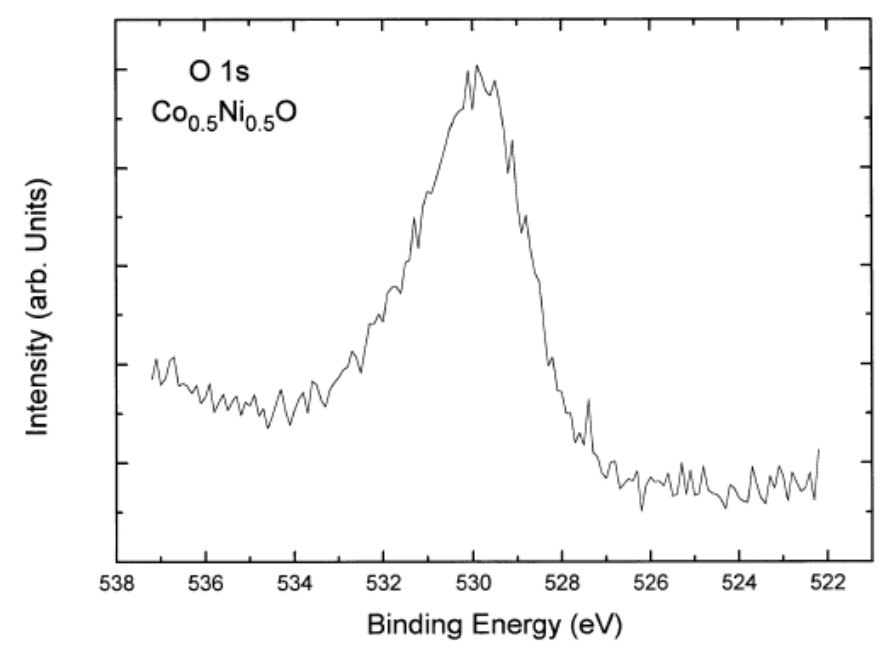

Figure 6. Oxygen $1 \mathrm{~s}$ XPS for the $\mathrm{Co}_{0.5} \mathrm{Ni}_{0.5} \mathrm{O}$ solid solution. 
metal $2 \mathrm{p}$ spectra for the solid solutions at or below this composition are highly characteristic of rocksalt monoxide data in both their peak-shapes and binding energies. The oxygen $\mathrm{O}$ 1s peak has been used as an internal standard for calibration of binding energies, a practice that has worked well for $\mathrm{CoO}(100)$ and $\mathrm{NiO}(100)$ surfaces whose $\mathrm{O} 1 \mathrm{~s}$ values have been reported to be $529.5 \pm 0.1$ $\mathrm{eV}$ for these surfaces under a wide range of oxidizing and reducing conditions $[13,19]$.

Calibrating the nickel and cobalt $2 \mathrm{p}$ binding energies to a $529.5-\mathrm{eV} \mathrm{O} 1 \mathrm{~s}$ lattice oxygen standard yields values of $854.6 \mathrm{eV}$ for the nickel $2 \mathrm{p}_{3 / 2}$ and $780.2 \mathrm{eV}$ for the cobalt $2 \mathrm{p}_{3 / 2}$ transitions for solid solutions with bulk $x$ values that are $\leq 0.5$ to within $\pm 0.2 \mathrm{eV}$, which is within the estimated error of the measurement and indicates that the chemical environment of the metal cations remains indistinguishable by XPS in this concentration range. The binding energies are in good agreement with those of $2 \mathrm{p}_{3 / 2}$ transitions observed for well-defined

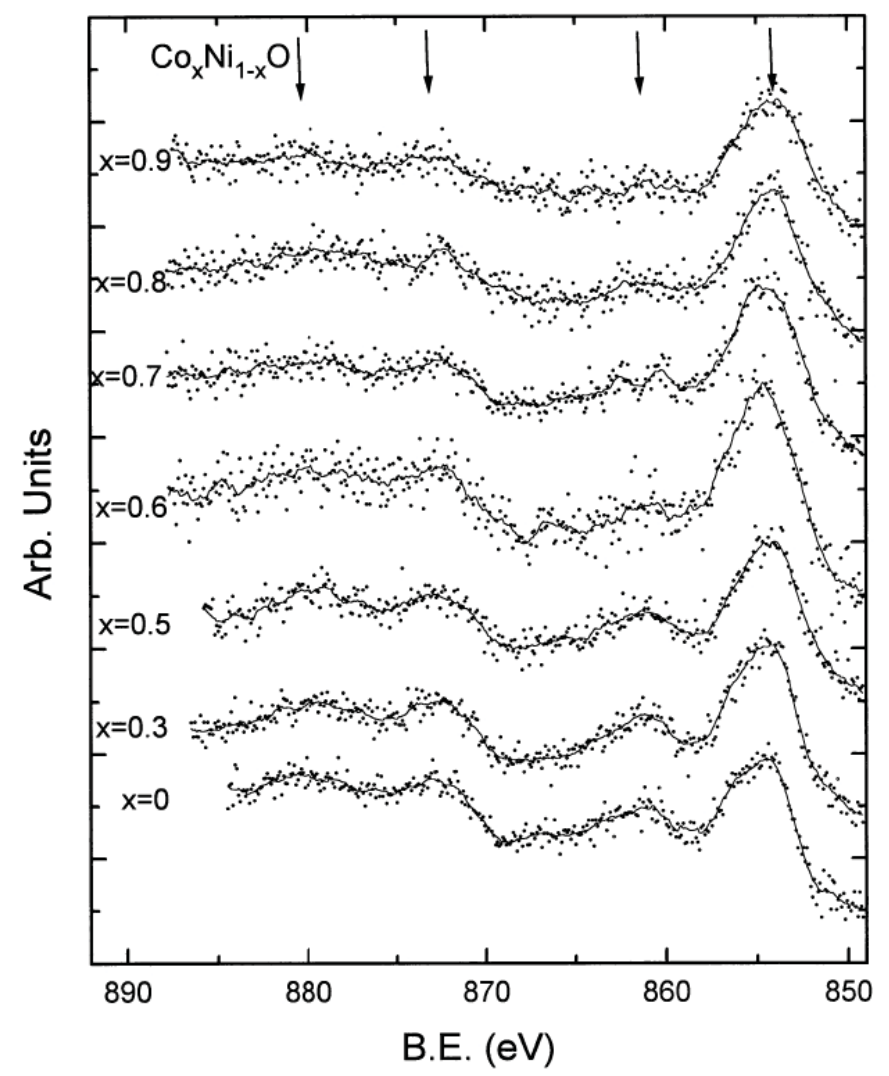

Figure 7. Nickel $2 \mathrm{p}$ XPS for the $\mathrm{Co}_{x} \mathrm{Ni}_{1-x} \mathrm{O}$ solid solutions over the range of bulk $x$ values. Arrows at the top of the $x$ $=0.9$ spectrum emphasize spectral changes described in the text. Discrete points represent actual data and the solid lines are three point smoothed fits to the data. surfaces of the bulk $\mathrm{CoO}$ [13] and $\mathrm{NiO}$ [19] single crystals. In addition, the satellite structure, which has been particularly well-studied for charge-transfer $3 \mathrm{~d}$ rocksalt monoxides [20-24], is characteristic of photoemission from $\mathrm{CoO}$ and NiO-like materials. The main and satellite peaks (Figure 4 and Figure 5) result from different final states accessible through the band structure of the $3 \mathrm{~d}$ rocksalt monoxides; the satellite has been identified with a final state of $2 \mathrm{p}^{5} 3 \mathrm{~d}^{8}$ and the main peak assigned to $2 \mathrm{p}^{5} 3 \mathrm{~d}^{9} \underline{\boldsymbol{L}}$ where $\underline{\boldsymbol{L}}$ represents a hole in the $2 \mathrm{p}$ level of a neighboring lattice oxide. Deviation from rocksalt stoichiometry in either direction, through reduction to produce lattice oxygen vacancies or through oxidation to form spinel or other oxide materials, has been shown to decrease the intensity of the satellites dramatically [13].

Significant peak shape changes in the Ni 2p data (Figure 7) are observed over the range in which deviations from bulk stoichiometry is observed at the surface. Not only do the satellites decrease in intensity in this range, but there is a dramatic shift away from the one-to-two ratio of the $2 p_{1 / 2}$ to $2 p_{3 / 2}$ intensities expected from simple degeneracy arguments to favor the $2 p_{3 / 2}$ final state transition. This is a clear indication of a change in surface magnetic properties from that of the bulk, which is antiferromagnetic in the monoxide solid solutions, to something that couples more strongly to the $2 \mathrm{p}_{3 / 2}$ state, where the electron is photoejected with its spin parallel to the orbital angular momentum, than to the antiparallel $2 p_{1 / 2}$ final state. Changes that occur in the cobalt $2 p$ region are considerably more subtile and are most obvious in the region of $x=0.6-0.7$ (Figure 8), where there is a decrease in the $2 p$ satellite structure and an appearance of a lower binding energy species, found as a shoulder at $779.6 \mathrm{eV}$ for the $2 \mathrm{p}_{3 / 2}$ transition. The changes are similar to those reported for $\mathrm{Co}_{3} \mathrm{O}_{4}$ epitaxies formed upon oxidation of $\mathrm{CoO}(100)$ single crystal surfaces [13] and are comparable to the Co $2 \mathrm{p} \mathrm{XP}$ spectra of $\mathrm{Co}_{3} \mathrm{O}_{4}$ powdered samples $[25,26]$.

Concentration information may also be obtained from XPS intensities. Sensitivity factors for the various transitions were estimated by assuming an exponential escape depth energy dependence for the photoelectron

$$
I_{i}=I_{0} \sum_{n=0}^{\infty} C_{i} \sigma_{i} \exp \left(-\frac{n x}{\lambda_{i} \cos \theta}\right),
$$

where $I_{i}$ is the integrated peak intensity for the $i$ th el- 
ement, $I_{0}$ is the X-ray photon fluence for the XP spectrum, $C_{i}$ is the concentration of the $i$ th element in the $n$th layer into the solid surface, $\sigma_{i}$ is the photoemission cross-section for the transition of interest from the $i$ th element, $x$ is the distance between layers in the crystal lattice, $\lambda_{i}$ is the mean free path for an electron with kinetic energy appropriate to the transition of interest and $\cos \theta$ corrects for the analyzer detection angle. The mean free paths were calculated by Penn's method [27] and photoemission cross-sections were obtained from Scofield [28]. Assuming the concentration of the element to be homogeneous in the near-surface region, a sensitivity factor similar to that used in the Auger analysis may be defined and the concentration proportional to the XPS peak intensity:

$$
C_{i}=\frac{I_{i}}{S_{i} I_{0}}
$$

can be used by methods analogous to those of Equation 1 and Equation 2 to obtain information similar to that of Figure 2 and Figure 3. Note that since $I_{0}$ is assumed

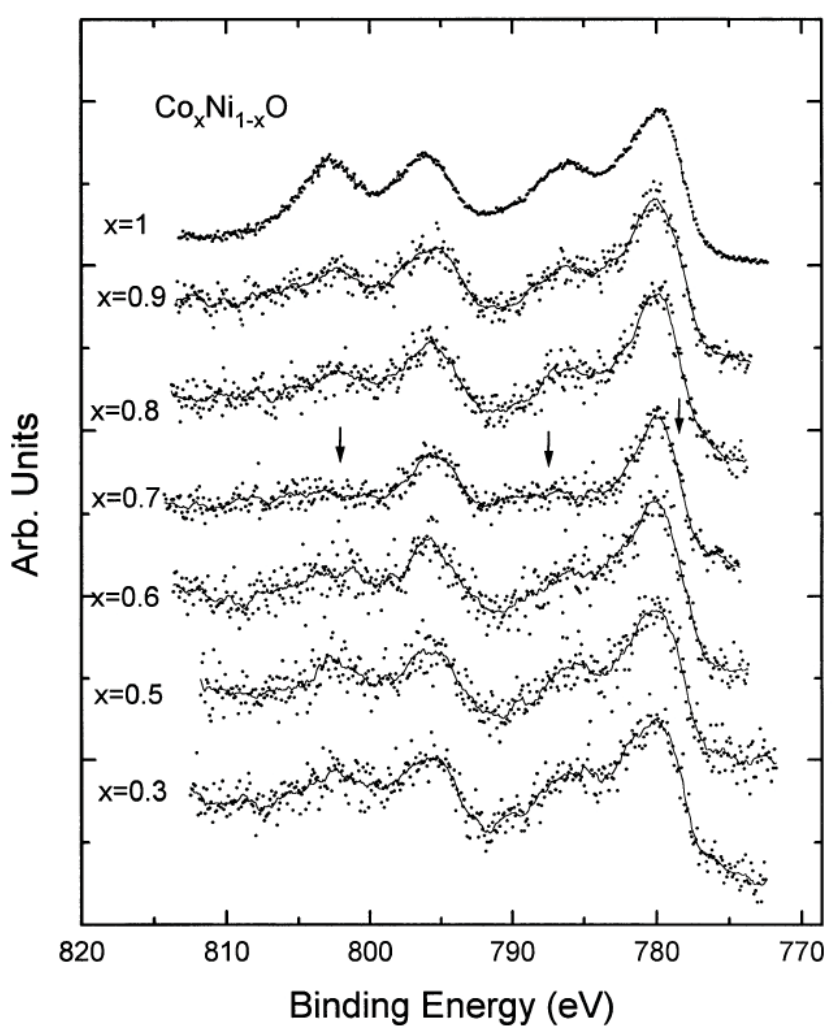

Figure 8. Cobalt $2 \mathrm{p}$ XPS for the $\mathrm{Co}_{x} \mathrm{Ni}_{1-x} \mathrm{O}$ solid solutions over the range of bulk $x$ values. Arrows at the top of the $x=$ 0.7 spectrum emphasize spectral changes described in the text. Descrete points represent actual data and the solid lines are three point smoothed fits to the data. constant within a given series of measurements, taking ratios of intensities causes the term to cancel and obviates the need to determine it. Cobalt fractional surface concentrations are plotted vs. $x_{\text {bulk }}$ in Figure 9 and show similar deviations in surface stoichiometry to that of the Auger data (Figure 2) for $x \gtrsim 0.6$.

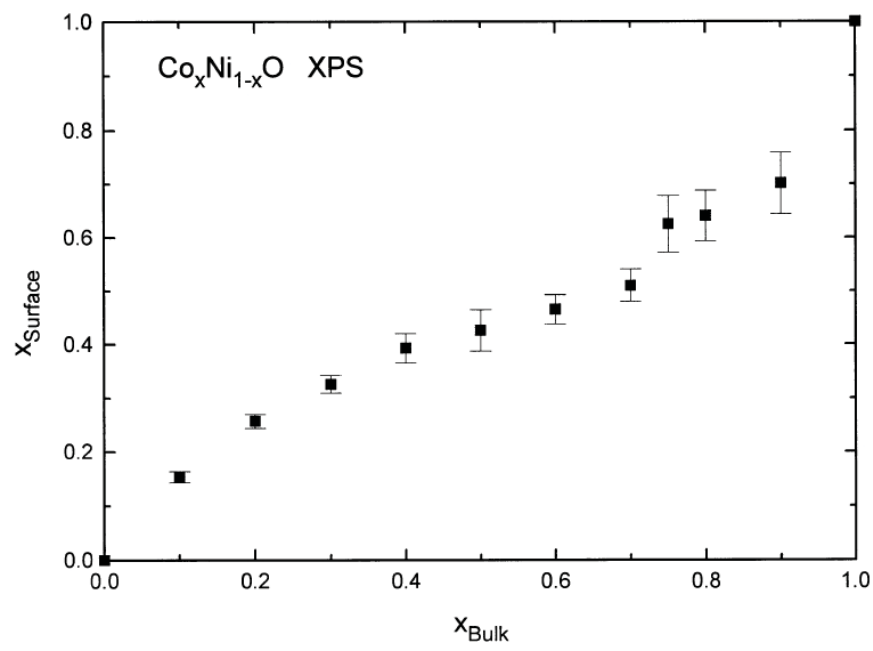

Figure 9. Surface ( $\left.x_{\text {surface }}\right)$ cobalt concentration as a function of the bulk ( $\left.x_{\text {bulk }}\right)$ value, measured by XPS. Error bars represent uncertainty in determining peak intensities in the peak fitting procedure.

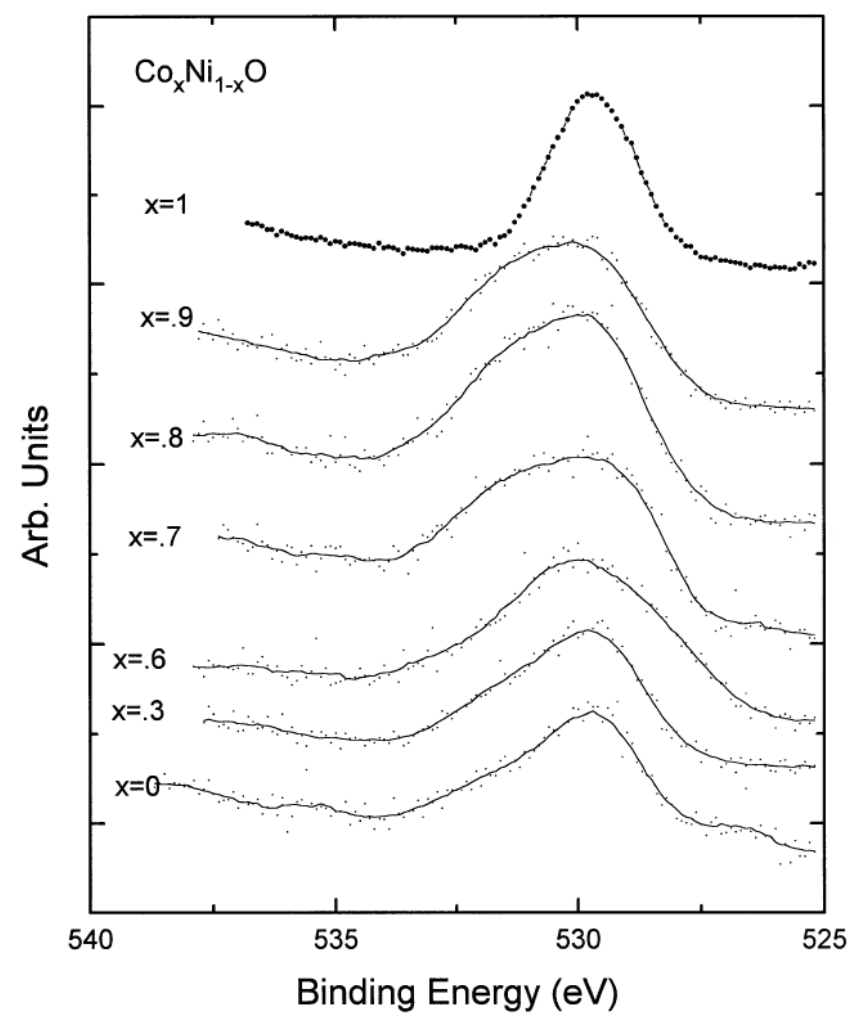

Figure 10. Oxygen $1 \mathrm{~s}$ XPS for the $\mathrm{Co}_{x} \mathrm{Ni}_{1-x} \mathrm{O}$ solid solutions over the range of bulk $x$ values. 


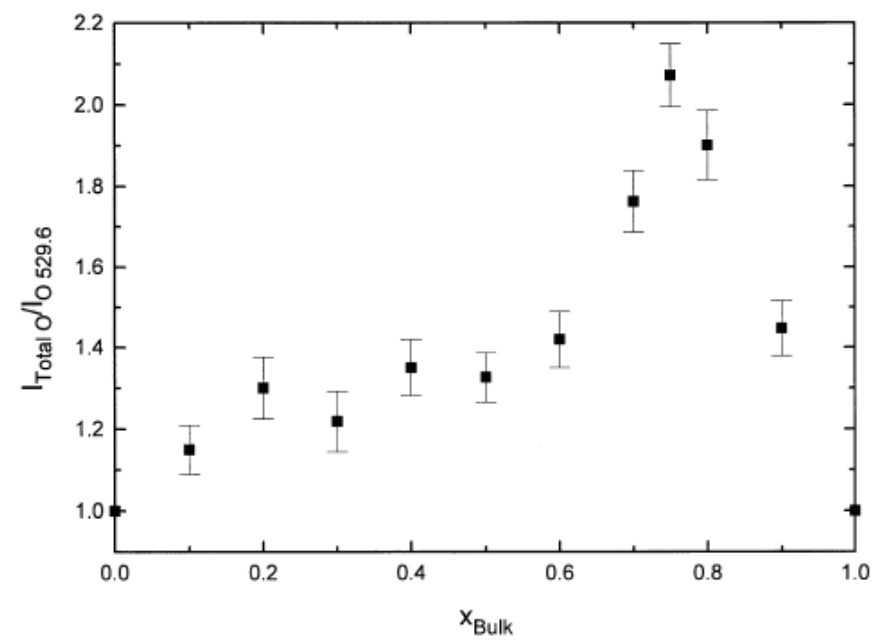

Figure 11. Ratio of the total $(531.2+529.5 \mathrm{eV})$ to $529.5 \mathrm{eV} \mathrm{O}$ 1s XP spectral intensities as a function of the bulk $x$ value. Error bars represent uncertainty in determining peak intensities in the peak fitting procedure.

Oxygen concentrations calculated from XPS intensity ratios relative to that of the total metal $(\mathrm{Ni}+\mathrm{Co})$ are $0.90 \pm 0.25$ across the series, within error of the value expected for the monoxide. Unfortunately, the XPS intensity data are too noisy to distinguish between monoxide and spinel oxygen concentrations and there is no clear trend visible in XPS O 1s to total metal intensity ratios. The oxygen spectrum is further complicated by the formation of a second peak to higher binding energy of the $529.5 \mathrm{eV}$ lattice peak. This causes the O $1 \mathrm{~s}$ peak to broaden considerably, with the maximum effect observed in the $x_{\text {bulk }}=0.6-0.7$ solid solution concentration region (Figure 10). The $\mathrm{O} 1 \mathrm{~s}$ spectrum can be fit to two dominate contributions, one associated with the main lattice peak at $529.5 \mathrm{eV}$ that is fairly constant in intensity and another of variable intensity at $531.2 \mathrm{eV}$.

A plot of the total $\mathrm{O} 1 \mathrm{~s}$ intensity relative to that of the $529.5 \mathrm{eV}$ oxygen lattice species is shown in Figure 11 as a function of $x_{\text {bulk }}$. For low $x$ values, higher binding energy contributions to the $\mathrm{O}$ 1s peak may well be due to surface hydroxylation as a result of exposure of the $\mathrm{Co}_{x} \mathrm{Ni}_{1-x} \mathrm{O}$ samples to air in transferring them from the quartz capsules in which they were annealed to the UHV chamber. However, these contributions are only $10-20 \%$ of the total O $1 \mathrm{~s}$ intensity for $x \lesssim 0.5$. As the bulk concentration range approaches that of $x=0.6-0.7$, the peak shape for the O 1s XPS transition broadens considerably until the higher energy peak dominates the XP spectrum. Comparable O 1s XPS structure has been observed be- fore upon polycrystalline $\mathrm{Co}_{3} \mathrm{O}_{4}$ samples, and although the identity of the higher binding energy $\mathrm{O} 1 \mathrm{~s}$ species has not been unequivocally identified, it is most likely due to some sort of surface oxide defect [29]. Similar changes in the $\mathrm{O} 1 \mathrm{~s}$ peak structure have also been observed for cobalt monoxide as it is oxidized to $\mathrm{Co}_{3} \mathrm{O}_{4}$ [25] and for $\mathrm{Co}_{3} \mathrm{O}_{4}$-like epitaxies that have formed on $\mathrm{CoO}(100)$ [13]. In these cases, the $531.2 \mathrm{eV}$ peak has been observed to rival the lattice oxygen peak in intensity, even for cases in which large amounts of surface hydroxyls can be eliminated as a source of surface contamination [13].

\section{Discussion}

Cobalt monoxide and nickel monoxide form solid solutions with the rocksalt structure and the composition $\mathrm{Co}_{x} \mathrm{Ni}_{1-x} \mathrm{O}$ over all possible range of compositions $0 \leq$ $x \leq 1$. In the bulk of the material, the metal cation distribution is homogeneous and the lattice parameter varies linearly with $x$ from $a=4.1684 \AA$ for $\mathrm{NiO}(x=0)$ to $a$ $=4.2667 \AA$ for $\mathrm{CoO}(x=1)$, in agreement with Vegard's law [4]. Auger and XPS intensity data presented here indicate that the surface composition presents a more complicated picture. While surface and bulk compositions are comparable for low $x$ values, deviations that are consistent with the formation of the known bulk material $\mathrm{NiCo}_{2} \mathrm{O}_{4}$ occur for bulk concentrations of approximately $0.6-0.7$.

XPS peak shape changes in the Ni $2 p$, Co $2 p$, and $\mathrm{O} 1 \mathrm{~s}$ regions also indicate compositional changes at the surfaces of these materials over the same concentration ranges. The cobalt core $2 p$ levels show the most subtile effects, but these are also the most straightforward to interpret. The intensity of the satellite structure decreases and an additional lower binding energy peak appears as the anomalous surface composition forms, as is observed for $\mathrm{Co}_{3} \mathrm{O}_{4}$ and $\mathrm{Co}_{3} \mathrm{O}_{4}$-like epitaxies. The lower binding energy peak, observed as a shoulder at $2 \mathrm{p}_{3 / 2}=$ $779.6 \mathrm{eV}$, is attributed to tetrahedrally coordinated $\mathrm{Co}^{2+}$ in the pure $\mathrm{Co}_{3} \mathrm{O}_{4}$ samples $[13,26,30,31]$. The octahedrally coordinated cobalt cations of $\mathrm{CoO}[13,29-31]$ and $\mathrm{Co}_{3} \mathrm{O}_{4}[13,29-31]$ have comparable binding energies generally reported to be within $\pm 0.2 \mathrm{eV}$ of each other at approximately $2 \mathrm{p}_{3 / 2}=780.5 \mathrm{eV}$ despite the difference in their oxidation states. This illustrates the diffi- 
culty in distinguishing among specific cation $2+/ 3+$ oxidation states and site occupancies for cobalt oxides by XPS binding energy alone. Variable final state effects and small shifts between the two oxidation states make unequivocal determination of chemical environment difficult, particularly if several different sites and oxidation state species are present.

Nickel $2 p$ binding energies are also quite constant with variations in the solid solution concentration and the $2 \mathrm{p}_{3 / 2}$ value is measured to be $854.6 \pm 0.2 \mathrm{eV}$ across the series. $\mathrm{Ni}^{3+}$ species in solid state oxides have generally been reported with binding energies approximately $1.5 \mathrm{eV}$ higher than this value $[32,33]$. The data are, therefore, inconsistent with $\mathrm{Ni}^{3+}$ as a dominant species in the near-surface region for the $\mathrm{Co}_{x} \mathrm{Ni}_{1-x} \mathrm{O}$ solid solutions, regardless of composition. Tetrahedrally coordinated $\mathrm{Ni}^{2+}$, for example in $\mathrm{NiAl}_{3} \mathrm{O}_{4}[32,33]$ and $\mathrm{NiCr}_{2} \mathrm{O}_{4}$ [34], has also been reported with binding energies 1-2 eV larger than those observed here. Therefore, even in the range of $x=0.6-0.7$ where the spinel compound appears to be forming, the nickel species is predominantly octahedrally coordinated $\mathrm{Ni}^{2+}$. This suggests that the nickel-enriched material forming at $x \approx 0.6$ bulk cobalt concentration is an inverse spinel structure with the classic cationic distribution of $\mathrm{Co}^{3+}\left[\mathrm{Ni}^{2+}, \mathrm{Co}^{3+}\right] \mathrm{O}_{4}$, where the bracketed cations are octahedrally coordinated and those preceding the bracket are tetrahedrally coordinated.

In its bulk form, $\mathrm{NiCo}_{2} \mathrm{O}_{4}$ has been characterized by X-ray diffraction [7], neutron diffraction [7], Mössbauer spectroscopy [35], EXAFS [35], and XANES [35]. While nominally classified as an inverse spinel, variations in site occupancy have been proposed and the bulk magnetic properties have been interpreted as more in line with a distribution of site occupancies given by $\mathrm{C}$ $\mathrm{o}_{\delta}{ }^{2+} \mathrm{Co}_{1-\delta}{ }^{3+}\left[\mathrm{Ni}_{1-\delta}{ }^{2+} \mathrm{Ni}_{\delta}{ }^{3+} \mathrm{Co}^{3+}\right] \mathrm{O}_{4}$ with a range of $\delta$ values reported by various laboratories [7]. While some small fraction of nickel may be present as $\mathrm{Ni}^{3+}$ in the XP spectra of Figure 7, the majority appears to be octahedrally coordinated $\mathrm{Ni}^{2+}$. This may represent a difference in the spinel-like surface that forms on the $\mathrm{Co}_{x} \mathrm{Ni}_{1-x} \mathrm{O}$ solid solutions compared to native $\mathrm{NiCo}_{2} \mathrm{O}_{4}$ surfaces. It also may be due to variation in $\delta$ with synthetic or ambient conditions, or to differences between the surface and bulk properties of the $\mathrm{NiCo}_{2} \mathrm{O}_{4}$ material, itself.

A final comment should be made on the evolution of the $\mathrm{O} 1 \mathrm{~s}$ core photoemission spectrum. The species ap- pearing at $531.2 \mathrm{eV}$ has been previously observed on a number of surfaces related to $\mathrm{Co}_{3} \mathrm{O}_{4}$ and mixed metal oxide spinel surfaces. While it has been attributed to a number of potential effects, the origin of this second peak has never been adequately identified. Unfortunately, the binding energy is consistent with surface hydroxylation, and for mixed metal oxide solutions formed by the thermal decomposition of hydroxides or from hydroxyl-containing solvents $[36,37]$, this may well be the case. However, very large $531.2 \mathrm{eV} \mathrm{O} 1$ s peaks have been observed to form under dry conditions where surface hydroxylation has been eliminated as a major surface impurity, for example, by high resolution electron energy loss spectroscopy [13].

A more likely assignment is for a defect oxygen species that can be present in large concentrations without destabilizing the lattice to the point that it cannot form a metastable thin film upon a templating transition metal oxide structure. The spinel unit cell is fairly extensive in size, containing 56 atoms per unit cell. However, in an ideal structure, there are only two different local environments for the cations, octahedral and tetrahedral sites, and only one for the closest packed lattice oxygen. Half of the octahedral sites and 7/8ths of the tetrahedral sites remain unfilled in the spinel structure and to ensure that all lattice oxygen species remained equivalent, the cation sites must be distributed uniformally and with a cation of the correct oxidation state. Any clustering of oxidation states or site occupancies could easily lead to a second type of lattice oxygen. While there is presently insufficient information for the unambiguous assignment of the $531.2 \mathrm{eV}$ species, it is clear that it results from the surface oxide thin film and not due to contamination from surface hydroxyls or related hydroxide compound formation.

\section{Conclusions}

Auger and X-ray photoelectron spectroscopies have been used to investigate the surface composition for the mixed metal oxide $\mathrm{Co}_{x} \mathrm{Ni}_{1-x} \mathrm{O}$ over the entire range of bulk $x, 0 \leq x \leq 1$. The surface and bulk compositions are comparable for $x<0.6$ and show XPS binding energies and peak shapes similar to those of the parent rocksalt monoxides, $\mathrm{CoO}$ and $\mathrm{NiO}$. The solid solutions are enriched in nickel for $\gtrsim 0.6$ and are pinned at a value 
compatible with the formation of a $\mathrm{NiCo}_{2} \mathrm{O}_{4}$ surface phase until the material is almost pure CoO. XPS indicates that the predominant form of nickel across the entire range of bulk concentrations is octahedrally coordinated $\mathrm{Ni}^{2+}$, implying that the $\mathrm{NiCO}_{2} \mathrm{O}_{4}$-like surface phase has an inverse spine structure. The nickel-enriched, spinel-like surface phase is also defect-riddled, giving rise to a second oxygen species at $531.2 \mathrm{eV}$ in the O 1s XP spectrum.

\section{Acknowledgements}

We are grateful to NSF for support of this project under grant CHE-9616690. We also gratefully acknowledge the State of Nebraska Research Initiative through the Center for Materials Research and Analysis.

\section{References}

1. D.G. Castner, P.R. Watson and I.Y. Chan. J. Phys. Chem. 93 (1989), p. 3188.

2. B.C. Gates and G.C.A. Schuit. J. Catal. 34 (1974), p. 68.

3. L. Passerini and G. Natta. Gazz. Chim. Ital. 59 (1929), p. 129.

4. W.D. Johnson, R.C. Miller and R. Mazelsky. J. Phys. Chem. 63 (1959), p. 198.

5. M.A. Tarasevich, B.N. Efermov, Electrodes of Conductive Metallic Oxides, Elsevier, Amsterdam, 1980, p. 221.

6. R.W.G. Wkchoff, Crystal Structures, Wiley, New York, 1963, pp. 86 and 89 .

7. O. Knop, K.I.P. Reid, Sutarno and Y. Nakagawa. Can. J. Chem. 46 (1968), p. 3463.

8. G. Blasse. Philips Res. Rep. 18 (1963), p. 383.

9. D. Mehanjiev and E. Nikolova-Zhecheva. Thermochemica Acta 51 (1981), p. 343.

10. Y.E. Roginskaya, O.V. Morozova, E.N. Lubnin, Y.E. Ulitina, G.V. Lopukhova and S. Trasatti. Langmuir 13 (1997), p. 464.

11. D. Pyke, K.K. Mallick, R. Reynolds and A.K. Bhattacharya. $J$. Mater. Chem. 84 (1998), p. 1095.

12. P. Nkeng, G. Poillerat, J.F. Koenig, P. Chartier, B. Lefez, J. Lopitaux and M. Lenglet. J. Electrochem. Soc. 142 (1995), p. 1777.
13. G.A. Carson, M.H. Nassir and M.A. Langell. J. Vac. Sci. Technol. A 143 (1996), p. 1637.

14. K.W. Wulser and M.A. Langell. Phys. Rev. B. 48 (1992), p. 9006.

15. L.E. Davis, N.C. MacDonald, P.W. Palmberg, G.E. Riach, R.E. Weber, Handbook of AES, Physical Electronics Industries, Eden Praire, 1976, pp. 89 and 93.

16. S. Mroczkowski and D. Lichtman. J. Vac. Sci. Technol. A 34 (1985), p. 1860.

17. S. Mroczkowski and D. Lichtman. Surf. Sci. 127 (1983), p. 121.

18. S. Mroczkowski and D. Lichtman. Surf. Sci. 131 (1983), p. 159.

19. M.A. Langell and M.H. Nassir. J. Phys. Chem. 99 (1995), p. 4162.

20. R.P. Furstenau, G. McDougall and M.A. Langell. Surf. Sci. 150 (1985), p. 55.

21. M. Takahashi and J. Igarashi. Phys. Rev. B 54 (1996), p. 13566.

22. D.E. Eastman and J.L. Freeouf. Phys. Rev. Let. 34 (1975), p. 395.

23. M. Tomellini. J. Electron Spectrosc. Relat. Phenom. 58 (1992), p. 75 .

24. J. Hugel and M. Belkhir. Solid State Commun. 73 (1990), p. 159.

25. M. Oku and Y. Sato. Appl. Surf. Sci. 55 (1992), p. 37.

26. C.R. Brundle, T.J. Chuang and D.W. Rice. Surf. Sci. 60 (1976), p. 286.

27. D.R. Penn. J. Electron Spectrosc. Relat. Phenom. 9 (1976), p. 29.

28. J.H. Scofield. J. Vac. Sci. Technol. A 8 (1976), p. 129.

29. V. M Jimènez, A. Fernàndez, J.P. Espinòs and A.R. GonzàlezElipe. J. Electron Spectrosc. Relat. Phenom. 71 (1995), p. 61.

30. J. Grimbolt, J.P. Bonnelle and J.P. Beaufils. J. Electron Spectrosc. Relat. Phenom. 8 (1976), p. 437.

31. B. Marcus-Saubat, J.P. Beaufils and Y. Barbaux. J. Chim. Phys. 83 (1986), p. 317.

32. D. Briggs, M.P. Seah, Practical Surface Analysis, Wiley, New York, 1990, 641.

33. G.C. Allen, S.J. Harris, J.A. Jutson and J.M. Dyke. Appl. Surf. Sci. 37 (1989), p. 111.

34. L. Salvati, L.E. Makovsky, J.M. Stencel, F.R. Brown and D.M. Hercules. J. Phys. Chem. 85 (1981), p. 3700.

35. M. Lenglet, R. Guillamet, J. Dürr, D. Gryffroy and R.E. Vandenberghe. Solid State Commun. 74 (1990), p. 1035.

36. Y.E. Roginskaya, O.V. Morozova, E.N. Lubnin, Y.E. Ulitina, G.V. Lopukhova and S. Trasatti. Langmuir 13 (1997), p. 4621.

37. J.P.S. Badyal, X. Zhang and R.M. Lambert. Surf. Sci. Lett. 225 (1990), p. L15. 